http://heanoti.com/index.php/hn

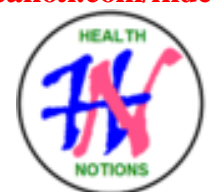

RESEARCH ARTICLE

URL of this article: http://heanoti.com/index.php/hn/article/view/hn30306

\title{
Genetic Variation of I/D Enzyme Converting Angiotensin (ACE) with Athlete Muscle
} Resistance

\author{
Indriono Hadi $^{1(\mathrm{CA}),}$ Ilham Patelongi ${ }^{2,}$ Lilin Rosyanti ${ }^{3}$ \\ ${ }^{1(\mathrm{CA})}$ Department of Nursing, Health Polytechnic of Kendari, Indonesia; indrionohadi@gmail.com \\ (Corresponding Author) \\ ${ }^{2}$ Department of Medical Physiology, Hasanuddin University, Makassar, Indonesia \\ ${ }^{3}$ Department of Nursing, Health Polytechnic of Kendari, Indonesia; lilin6rosyanti@gmail.com
}

\begin{abstract}
Programmed physical exercise in athletes causes the cardiovascular system to be more efficient in pumping blood and carrying oxygen to muscles. Indicators of cardiovascular changes during exercise are: oxygen consumption, heart rate, stroke volume, differences in arterial and venous oxygen, blood pressure and blood flow. Some physical components that need to be considered for development include: VO2 max, muscle endurance, strength, flexibility, speed, stamina, agility, and explosive power. Some specific genes are identified as a muscle phenotype response to strength training, namely angiotensin-converting enzyme (ACE), which converts angiotensin I to angiotensin II. The insertion / deletion (I/D) polymorphism in this gene was found to play a role in variations in the activity of the ACE enzyme, in someone carrying a deletion allele (D) who had higher ACE enzyme activity. The research was carried out at the Organization of the Indonesian National Sports Committee (KONI), especially in South Sulawesi Bangkit athletes. The results showed a significant relationship between genetic variation in ACE gene (I/D) with muscle endurance (p-value <0.05). Whereas in physical exercise (Sit Up, Push Up, Squat Jump) with ACE Gene Variation there was no relationship (p-value $>0.05$ ). Likewise in sprints and endurance sports, there was no relationship with variations in the ACE gene (p-value $>0.05$ ). In conclusion, further research should be on athletes who win the Olympics or World Championships, with a single sports discipline, larger sample sizes and more diverse genetic variations, so that the ACE genotype can be explored and developed in athletes.
\end{abstract}

Keywords: Athlete, Physical exercise, ACE gene, Genetic variation of I / D, Muscle endurance

\section{INTRODUCTION}

\section{Background}

Programmed physical exercise such as athletes will make the cardiovascular system more efficient in pumping blood and carrying oxygen to muscles. This exercise is very good for increasing the capacity of the cardiovascular system. Indicators of cardiovascular changes during exercise are: oxygen consumption, heart rate, stroke volume, differences in arterial and venous oxygen, blood pressure and blood flow. Several studies regarding the relationship between the presence of alleles from the angiotensin-converting enzyme (ACE) gene coding with individual endurance or capacity capacity ${ }^{(1)}$ Sports coaching is carried out and fostered by most sports branch organizations, in the context of preparing athletes for championships such as PON, national championships and international events, so training is needed through training programs that require control, evaluation and change. Every training and development must be observed and documented. Furthermore, with the control in the form of tests and then look at the results of the exercise during the training program. Some physical components that need to be considered for development include: VO2 max, muscle endurance, strength, flexibility, speed, stamina, agility, and explosive power. The response to strength training varies greatly between individuals and is highly questioned by genetic variables, which at present, have not yet been identified $^{(2) \text {. }}$

Muscle strength and mass are inherited phenotypes, with heritability of $14-80 \%$ for strength and $20-85 \%$ for muscle mass. Although the adaptation heritability of this muscle phenotype to muscle strength training has 
not been well studied, the adaptive response also seems to have a genetic component. Several specific gene candidates have been identified for the muscle phenotype's response to strength training. One gene that has emerged as a candidate is angiotensin-converting enzyme (ACE), which converts angiotensin I to angiotensin II. The insertion / deletion (I/D) polymorphism in this gene was found to play a role in variations in the activity of the ACE enzyme, in someone carrying a deletion allele (D) having a higher ACE enzyme activity. Homozygotes for allele I (II) have much less ACE activity than heterozygotes (ID), and heterozygotes have lower ACE activity, than homozygotes for D alleles (DD) ${ }^{(3)}$. Angiotensin converting enzyme is coded by the ACE gene found on chromosome 17. Genetic variation of the ACE gene is characterized by the addition (Insertion = I) or reduction (Delesi $=\mathrm{D}$ ) of 287 DNA base pairs on the 16th intron of the ACE gene. Genetic variation (I/D) of ACE gene consists of three genotypes namely homozygous (DD), heterozygous I or D and homozygous II, where ACE levels are found highest in (DD) genotype, then followed (ID) and lowest in genotype II, with variation between 30-50\%. Because genotypes (DD) have higher ACE levels than (ID) and (II), theoretically they have higher Angiotensin II levels, both in plasma and in tissues. The ACE gene also inactivates bradykinin which is a vasodilator and antiproliferative substrate. High ACE levels cause bradykinin in the circulation and in the tissues is reduced, which in turn causes the ability of vascular vasodilation and anti-proliferative effects on tissue is reduced ${ }^{(3)}$.

An enzyme genotype variant (ACE) is an important factor in the hypertrophic response of the heart muscle to exercise and can also be involved in skeletal muscle hypertrophy - an important factor in the response to functional overload. Consistent genotypes and training interactions (ID/DD/II) were observed in all measures of strength, and training. The ACE genotype is the first genetic factor identified in skeletal muscle response to strength training. The relationship of ACE (I/D) polymorphisms with the response of the heart and bone muscles to functional overload suggests that they can share the same mechanism. These findings illustrate a new mechanism, which involves the renin-angiotensin system ${ }^{(2)}$, so that it is important to understand the role of the ACE gene with physical performance and how this gene can change the subject's ability to respond to exercise but can have important implications in designing studies to test therapeutic interventions, which will influence clinical practice ${ }^{(1),(4)}$

\section{METHODS}

\section{Population and sample}

This research was conducted at the Organization of the Indonesian National Sports Committee (KONI) of South Sulawesi Province, especially at the South Sulawesi Bangkit (SSB) athlete. Athlete's blood sample is taken and the next step is to check the ACE level at the Hasanuddin University Research Center (PKP). The population of all SSB athletes consisting of several sports branches in 2010, examination of 112 athletes blood samples by PCR method to determine the genetic variation of ACE gene (I/D) obtained the results of 26 people, from 11 sports, consisting of 13 athletes who have genotype II and 13 athletes who have DD genotype, only two types of gene variation were obtained, namely (DD) and (II) genotypes, while (I/D) did not obtain these variations.

\section{Research procedure}

How to measure ACE genes: Blood samples were collected as much as $5 \mathrm{ml}$ for each subject. From these samples extracted about $500 \mu \mathrm{g}$ DNA samples using the standard method. Genotive of RA system components amplified by Polymerase Chain Reaction (PCR) Reaction. Genetic variation of I / D ACE gene was determined by modification of the method from Rigat. The PCR primers used in this study were:

\section{GIIS : 5-CTCAAGCACGCCCCTCACAGGACTG-3; GAS : 5GATGTGGCCATCACATTCGTCAGAT-3; FYM : 5-ATCACGAGGTCAGGAGATCGAGAC-3.}

The initial stage of the new method is to amplify intron 16 through the insertion area (I) using primary GIIS and GAS flanking by heating for 1.30 minutes at $94{ }^{\circ} \mathrm{C}$ followed by 2 amplification cycles $\left(94{ }^{\circ} \mathrm{C}, 0.30\right.$ minutes; $62{ }^{\circ} \mathrm{C}, 1$ minute; $72{ }^{\circ} \mathrm{C}, 1$ minute) in $5 \mu \mathrm{L}$ buffer containing $2 \mathrm{~mm} \mathrm{MgCl}_{2}$ and $0.25 \%$ DMSO, using 0.5 $\mathrm{U}$ of Goldstar DNA poiymerase (Promega USA), and $20 \mu \mathrm{M}$ primary concentrations. The tube is then cooled for a moment at $4{ }^{\circ} \mathrm{C}$ and the FYM and GIIS primers are added to each $20 \mu \mathrm{m} /$ tube and the PCR reaction is continued for 30 cycles under the same conditions, then continued with 4 minutes for the extension process. The extension between GAS and GIIS results in a 561-bp PCR product for insertion alela (I), and 274-bp product for alela D. Further amplification between FYM and GIIS will result in 376-bp product which is only for insertion alela (i). After each genotive frequency is known, allela frequency is calculated according to the formula: allela 
frequency $\mathrm{D}=$ genotive frequency $\mathrm{DD}+1 / 2$ genotive frequency $\mathrm{ID}$, while alela frequency $\mathrm{I}=$ genotive frequency $\mathrm{II}+1 / 2$ genotive frequency ID, expressed in percent. The genetic variation of ACE gene I / D is the ACE gene I / D genotive determined by the PCR method which has been modified using the primers mentioned above. ${ }^{(5)}$

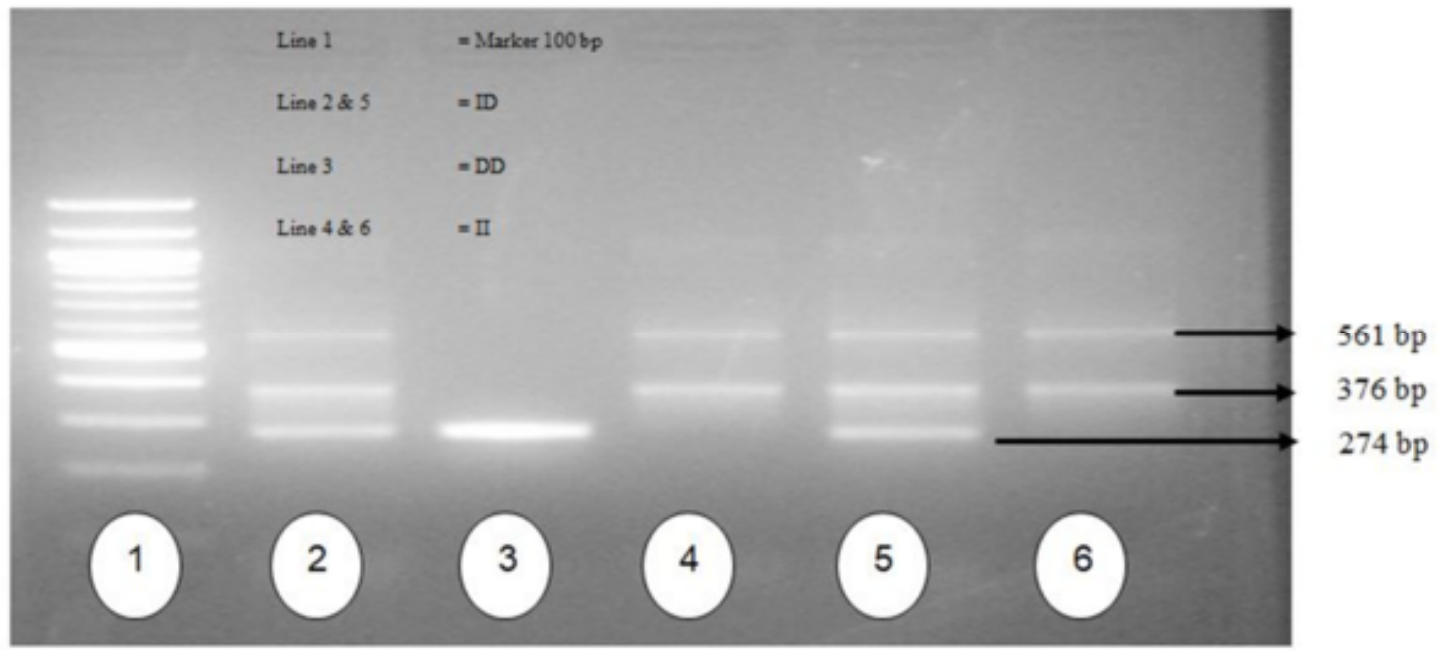

Figure 1. Genetic variation of I / D ACE genes determined by the modified PCR method

\section{RESULTS}

Test Analysis of Physical Exercise with ACE Gene Variations.

Table 1. The relationship between age and physical exercice (sit up, push up and squat jump)

\begin{tabular}{clccc}
\hline Age & \multicolumn{1}{c}{ Variable } & Enough & Good & p \\
\hline $16-35$ & Sit up & 11 & 15 & 0.169 \\
& Push up & 7 & 19 & 0.146 \\
& Squat jump & 4 & 26 & 0.165 \\
& Muscle Endurance & 4 & 22 & 0.165 \\
\hline
\end{tabular}

Table 1 shows there was no relationship between age and physical exercise (Sit Up, Push Up, Squat Jump) (p-value $>0.05$ ).

Table 2. The relationship between gender and physical exercice (sit up, push up and squat jump)

\begin{tabular}{ccccc}
\hline Variable & Gender & Enough & Good & p \\
\hline \multirow{2}{*}{ Sit up } & M & 6 & 5 & 0.279 \\
& F & 5 & 10 & \\
Push up & M & 3 & 8 & 0.973 \\
Squat jump & F & 4 & 11 & \\
& M & 3 & 8 & 0.150 \\
Muscle Endurance & F & 1 & 14 & \\
& M & 2 & 9 & 0.735 \\
\hline
\end{tabular}

Table 2 shows there was no relationship between sex and physical exercise (sit up, push up, squat jump) (p-value > 0.05). 
Table 2. The relationship between physical exercise (sit up, push up, squat jump) and ACE gene variations

\begin{tabular}{ccccc}
\hline \multirow{2}{*}{ Variable } & & \multicolumn{2}{c}{ ACE gene variations } & \multirow{2}{*}{ p } \\
& & II & DD & 0.234 \\
Sit up & Enought & 4 & 9 & \multirow{2}{*}{0.185} \\
Push up & Good & 9 & 6 & 11 \\
Squat jump & Enought & 2 & 8 & 0.277 \\
& Good & 5 & 12 & \multirow{2}{*}{0.048} \\
Muscle Endurance & Enought & 1 & 10 & \multirow{2}{*}{0.161} \\
Sprint & Good & 3 & 13 & \\
Endurance & Good & 0 & 9 & 12 \\
\hline
\end{tabular}

Table 3 shows that there was no relationship between physical exercise (sit up, push up, squat jump) and ACE Gene Variation (p-value $>0.05$ ), but the results of the analysis show a significant relationship $(\mathrm{p}<0.05)$ between variations genetic (I/D) ACE gene with muscular endurance. Whereas in sprint and endurance sports, there is no relationship with ACE gene variation, value ( $\mathrm{p}$-value >0.05)

\section{DISCUSSION}

The phenomenon of human physical performance in certain sports modalities has always been a target of interest for sports medicine specialists as well as sports physiologists. Regular exercise is the only therapy that is known to improve physical function in a person. However, there is considerable heterogeneity in response to exercise and data suggest that at least a portion of this variability can be attributed to genetic factors. Previous studies in younger people have shown that genetic variation in the angiotensin-converting-enzyme (ACE) gene is associated with physical performance variables and contributes to variability in training responses. The insertion / removal of the ACE enzyme (I/D) interacts with exercise to influence athletic performance, but the direction of the genotype effect depends on the outcome being assessed endurance vs. strength ${ }^{(5)}$.

The results of this study, with the analysis test there is a significant relationship between the ACE gene with muscle strength with a value $(\mathrm{p}=0,048)$. This is consistent with the theory of how the ACE gene catalyzes the conversion of angiotensin I to angiotensin II and the breakdown of bradykinin. The ACE gene interacts with physical exercise in the presence (insertion, allele I) which is associated with lower ACE activity and increased half-life of bradykinin. Excessive representation of this allele occurs in athlete endurance. In contrast, the D allele is associated with higher concentrations of angiotensin II (growth factor), a greater percentage of rapid muscle fiber contractions with increased strength due to training. Studies in younger people show the direction of the ACE (I/D) genotype effect depending on the type of training carried out and the results assessed (aerobic endurance vs. strength) ${ }^{(5)}$ allele D correlates performance improvement in power-based sports sprints, whereas allele insertion $\mathrm{I}$ is associated with a tendency to excellence in endurance sports ${ }^{(1)}$

Most published data focus on polymorphisms that describe the presence (insertion, allele I) or absence (deletion, allele D) of the order of 287-bp in intron 16, producing three genotypes: (II) and (DD), homozygous, and (ID), heterozygotes. Although polymorphisms occur in introns, this is a very strong and consistent marker for ACE activity in serum and tissue in different Caucasian populations ${ }^{(6)}$. There is a significant relationship between ACE gene and muscle strength, indicating the influence / significance of genes in phenotypes relevant to sports performance varies, in response to several factors, especially age. Allele D is associated with performance-oriented strength, and has been found to be generally increased in swimmers. Athletes running fast from a particular sport can complete their tasks during maximum training with a shorter duration of time compared to athletes of the same age and gender in endurance functions. The evaluation process requires reliability and application facilities, especially when athletes spend a lot of time competing, training and time spent during travel for training and competition activities. So the need for a test to minimize the possibility of interference and competition schedules such as isometric strength of hand grips, is used as a measure of total body strength ${ }^{(7)}$

According to the results of this research, several other studies that support, Thompson 2006, states that someone who has the genotive (DD) has a tendency to increase levels of ACE in the circulatory system that can trigger vascular vasoconstriction. So that it can be understood in an athlete who has genotype (II) has better endurance when compared to athletes who have (DD) genotype, so the importance of understanding the role of the ACE gene with physical performance and how this gene can change the subject's ability to respond to 
exercise and can has important implications in designing studies to test therapeutic interventions, so they will affect clinical practice ${ }^{(1)}$.

A number of studies have tried to measure the genetic contribution of physical phenotypes to skeletal muscle strength ${ }^{(8)}$. Based on differences in simple muscle mass and the strong influence of genetic variation in muscle function has been recognized ${ }^{(8),(9)}$. However, several specific candidate genes have been identified as significant for the response of muscle phenotypes ${ }^{(10),(11)}$. One of the genes that appears as a candidate is angiotensin-converting enzyme (ACE gene). The ACE gene plays a key role in regulating the renin-angiotensinaldosterone (RAS) system. ACE catalyzes the conversion of angiotensin I to angiotensin II and has an important role in electrolyte balance and systemic blood pressure ${ }^{(8),(10),(11) .}$

Studies investigating the relationship between ACE genotypes and skeletal muscle strength and mass phenotypes produce inconsistent findings. Some supporting studies, Moran et al, reported the results of studies with some physical, physiological, skill and lifestyle parameters in 1027 Greek adolescents, showing a strong association ( $\mathrm{P}<0.001)$ between ACE (I/D) polymorphisms (insertion / deletion) and grip strength and vertical jump in women, homozygous for allele I which shows higher performance-related phenotype scores, accounting for up to $4.5 \%$ of the phenotypic variant. This relationship is strongest in the dominant allel $\mathrm{D}$, with an average phenotypic value in heterozygous (I/D) close to the average value of homozygous (DD) ${ }^{(12)}$. Williams et al. reported a positive relationship between allele D and basic muscle strength. Folland et al. and Giaccaglia et al. both show interactions between genes and (ST: strength training), so that the allele carrier D (DD + ID) has a greater increase in strength induced by ST than genotype (II). ${ }^{(2),(5),(13) . ~ T h e ~ b a s i c ~ s t r e n g t h ~ o f ~ s k e l e t a l ~ m u s c l e, ~}$ shows a linear trend between decreases in type I fibers and increases in type IIb fibers from ACE (II) to (ID) and to (DD) genotypes. This finding has been proposed as a potential mechanism for the relationship between ACE $\mathrm{D}$ alleles and power-oriented athletic performance. ${ }^{(7),(14)}$

However, other researchers failed to support the finding that there was no relationship between ACE genes variation (II, DD) and (ID) on muscle strength. According to the results of this study, the absence of an association between ACE genes with physical exercise (Sit Up, Push Up, Squat Jump) with values (P>0.05) and muscle strength from both age and sex. Some that support the absence of an association between the ACE gene and physical training are; Pescatello et al. failed to support the relationship between the ACE allele D genotype and adaptation of muscle strength with $\mathrm{ST}^{(4),(8),(9),(12),}$ whereas other studies, of 192 athletes of male endurance athletes with oxygen uptake maximum $>/=75 \mathrm{ml} . \mathrm{kg}(-1) . \mathrm{min}(-1)$ and 189 male controls, ACE (ID) polymorphism in intron 16 by the three primary polymerase chain reaction method. There were no differences and changes in genotype frequency $(\mathrm{P}=0.214)$ and alleles $(\mathrm{P}=0.095)$ in both athletes and controls. Further analysis on athletes revealed no excess of allele I among athletes in the highest quartile (> $80 \mathrm{ml}$. Kg (-1). Min (1)) or decile (> $83 \mathrm{ml}$. Kg (-1). Min (-1)) maximal oxygen uptake, there is no relationship between ACE genes variation (II, DD) and (ID) on male endurance athletes. The controversial results reported are caused by factors related to sample size, research design, and phenotype measurements ${ }^{(10),(11),(14) .}$

Other studies that failed to support the ACE genotype (insertion / erasure) study of 62 men and 85 women participating in the US army. Pre and post basic training for 8 weeks, then determine the peak oxygen absorption and performance on the Physical Fitness Test with the Army Physical Fitness Test (APFT) scale, including the standard of endurance (sit-ups, push-ups) and run 2 miles. Subjects from different ACE genotypes have the same peak oxygen uptake and APFT scores, both pre and post training. Subjects with genotype (II) had higher APFT scores than others, but the difference was not statistically significant. In addition, no ACE genotype group had performance advantages in analyzes that were adjusted for initial fitness. So that the ACE genotype does not have a strong effect on aerobic power or muscular endurance in US Army participants ${ }^{(3,4,15) \text {. }}$

\section{CONCLUSION}

In conclusion, this study supports previous findings that further studies need to focus on athletes who are truly winners of the Olympics or World Championships, which are also single sport disciplines, with larger sample sizes and more diverse genetic variations, so that the ACE genotype can be explored and explored. developed on athletes.

\section{REFERENCES}

1. Thompson WR, Binder-Macleod SA. Association of genetic factors with selected measures of physical performance. Phys Ther. 2006;86(4):585-91.

2. Folland J, Leach B, Little T, Hawker K, Myerson S, Montgomery H, et al. Angiotensin-converting enzyme genotype affects the response of human skeletal muscle to functional overload. Experimental Physiology. 2000;85(5):575-9.

17 | Publisher: Humanistic Network for Science and Technology 
3. Charbonneau DE, Hanson ED, Ludlow AT, Delmonico MJ, Hurley BF, Roth SM. ACE genotype and the muscle hypertrophic and strength responses to strength training. Medicine and science in sports and exercise. 2008;40(4):677.

4. Pescatello LS, Kostek MA, Gordish-Dressman H, THOMPSON PD, SEIP RL, PRICE TB, et al. ACE ID genotype and the muscle strength and size response to unilateral resistance training. Medicine \& Science in Sports \& Exercise. 2006;38(6):1074-81.

5. Giaccaglia V, Nicklas B, Kritchevsky S, Mychalecky J, Messier S, Bleecker E, et al. Interaction between angiotensin converting enzyme insertion/deletion genotype and exercise training on knee extensor strength in older individuals. International journal of sports medicine. 2008;29(01):40-4.

6. Zhang B, Tanaka H, Shono N, Miura S, Kiyonaga A, Shindo M, et al. The I allele of the angiotensinconverting enzyme gene is associated with an increased percentage of slow-twitch type I fibers in human skeletal muscle. Clinical genetics. 2003;63(2):139-44.

7. Costa AM, Silva AJ, Garrido N, Louro H, Marinho DA, Marques MC, et al. Angiotensin-converting enzyme genotype affects skeletal muscle strength in elite athletes. Journal of sports science \& medicine. 2009;8(3):410.

8. Beunen G, Thomis M. Gene driven power athletes? Genetic variation in muscular strength and power. Br J Sports Med. 2006;40(10):822-3.

9. Beunen G, Thomis M. Gene powered? Where to go from heritability (h2) in muscle strength and power? Exercise and sport sciences reviews. 2004;32(4):148-54.

10. Rankinen T, Wolfarth B, Simoneau J-A, Maier-Lenz D, Rauramaa R, Rivera MA, et al. No association between the angiotensin-converting enzyme ID polymorphism and elite endurance athlete status. Journal of Applied Physiology. 2000;88(5):1571-5.

11. Rankinen T, Bray MS, Hagberg JM, Pérusse L, Roth SM, Wolfarth B, et al. The human gene map for performance and health-related fitness phenotypes: the 2005 update. Medicine \& Science in Sports \& Exercise. 2006;38(11):1863-88.

12. Moran CN, Scott RA, Wilson RH, Georgiades E, Goodwin W, Wolde B, et al. Increased frequency of an ACE polymorphism in Ethiopian elite marathon runners. Medicine \& Science in Sports \& Exercise. 2004;36(5):S259.

13. Williams AG, Day SH, Folland JP, Gohlke P, Dhamrait S, Montgomery HE. Circulating angiotensin converting enzyme activity is correlated with muscle strength. Medicine and science in sports and exercise. 2005;37(6):944-8.

14. Woods D, Brull D, Montgomery H. Endurance and the ACE I/D polymorphism. Science Progress (1933-). 2000:317-36.

15. Sonna LA, Sharp MA, Knapik JJ, Cullivan M, Angel KC, Patton JF, et al. Angiotensin-converting enzyme genotype and physical performance during US Army basic training. Journal of Applied Physiology. 2001;91(3):1355-63. 